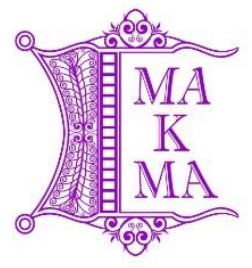

Majalah Kesehatan Masyarakat Aceh (MaKMA) http://ojs.serambimekkah.ac.id/index.php/makma

\title{
HUBUNGAN PERAN PETUGAS, DUKUNGAN KELUARGA DAN KEPATUHAN IBU HAMIL TERHADAP RENDAHNYA CAKUPAN PEMBERIAN TABLET Fe3 PADA IBU HAMIL (Studi Kasus di Wilayah Kerja Puskesmas Lampisang Kabupaten Aceh Besar)
}

\author{
T.M. Rafsanjani ${ }^{1 凶}$, Ifanda Kurniawan ${ }^{1}$, Irwan Saputra ${ }^{2}$, Evi Dewiyani ${ }^{1}$ \\ ${ }^{1}$ Fakultas Kesehatan Masyarakat Universitas Serambi Mekkah, ${ }^{2}$ Fakultas Kedokteran Universitas \\ Syiah Kuala.
}

${ }^{凶}$ Alamat Korespondensi: Fakultas Kesehatan Masyarakat Universitas Serambi Mekkah,
Lamgugob, Banda Aceh / tmrafsanjani@serambimekkah.ac.id / 085310750403

\begin{abstract}
ABSTRAK
Cakupan konsumsi tablet Fe3 pada ibu hamil di wilayah Puskesmas Lampisang hanya sebesar 20\%, hal ini dikarenakan petugas kesehatan kurang berperan dalam memberikan informasi tentang manfaat tablet $\mathrm{Fe} 3$ pada ibu hamil, tidak ada dukungan keluarga dan tidak patuh dalam konsumsi tablet Fe3. Penelitian ini bertujuan untuk mengetahui faktor yang berhubungan dengan rendahnya cakupan pemberian tablet $\mathrm{Fe} 3$ pada ibu hamil. Populasi dalam penelitian ini adalah ibu hamil sebanyak $276 \mathrm{ibu}$, dengan sampel sebanyak 73 responden dengan teknik sampel proportional sampling. Penelitian dilakukan pada tanggal 7-16 Agustus 2019, dengan pendekatan Cross Sectional. Analisis data menggunakan uji Chi-Square. Hasil uji univariat bahwa pemberian tablet $\mathrm{Fe} 3$ tidak tercapai $(64,4 \%)$, peran petugas kesehatan yang tidak berperan $(54,8 \%)$, ibu hamil yang tidak patuh $(60,3 \%)$ dan ada dukungan keluarga $(54,8 \%)$. Hasil uji bivariat diketahui bahwa ada hubungan peran petugas kesehatan dengan $\mathrm{p}$ value $=0,001$, dukungan keluarga dengan $p$ value $=0,001$ dan kepatuhan ibu hamil denagn $p$ value $=0,001$ ) dengan rendahnya cakupan pemberian tablet $\mathrm{Fe} 3$ pada Ibu hamil. Kesimpulan peran petugas kesehatan, dukungan keluarga dan kepatuhan ibu hamil merupakan faktor yang berhubungan dengan rendahnya cakupan pemberian tablet $\mathrm{Fe} 3$ pada Ibu Hamil di Wilayah Kerja Puskesmas Lampisang Kabupaten Aceh Besar Tahun 2019. Disarankan bagi puskesmas untuk meningkatkan kegiatan promosi kesehatan pada ibu hamil tentang pentingnya mengkonsumsi tablet $\mathrm{Fe} 3$.
\end{abstract}

Kata Kunci: Fe3, Ibu Hamil.

Riwayat Artikel 


\title{
RELATIONSHIP OF ROLE OF OFFICERS, FAMILY SUPPORT AND PREGNANCY
} OF PREGNANT WOMEN TO THE LOW COVERAGE OF PROVISION OF Fe3 TABLETS IN PREGNANT MOTHERS (Case Study in the Work Area of Lampisang in Aceh Besar District)

\begin{abstract}
Coverage of $\mathrm{Fe} 3$ tablet consumption in pregnant women in the Lampisang Health Center area is only $20 \%$, this is because health workers have less role in providing information about the benefits of $\mathrm{Fe} 3$ tablets to pregnant women, there is no family support and are not compliant in consuming Fe3 tablets. This study aims to determine the factors associated with the low coverage of Fe3 tablets in pregnant women. The population in this study were 276 pregnant women, with a sample of 73 respondents using proportional sampling technique. The study was conducted on 7-16 August 2019, using a cross sectional approach. Data analysis using Chi-Square test. Univariate test results showed that $\mathrm{Fe} 3$ tablets were not achieved (64.4\%), the role of health workers who did not play a role (54.8\%), non-compliant pregnant women (60.3\%) and family support $(54.8 \%)$ . Bivariate test results revealed that there is a relationship between the role of health workers with $p$ value $=0.001$, family support with $p$ value $=0.001$ and compliance with pregnant women with $\mathrm{p}$ value $=0.001)$ with the low coverage of $\mathrm{Fe} 3$ tablet delivery to pregnant women. Conclusion The role of health workers, family support and compliance of pregnant women is a factor related to the low coverage of Fe3 tablet delivery for pregnant women in the Work Area of Lampisang Health Center in Aceh Besar Regency in 2019. It is recommended for puskesmas to increase health promotion activities for pregnant women regarding the importance of consuming tablets $\mathrm{Fe} 3$
\end{abstract}

Keywords: Fe3, Pregnant Women. 


\section{PENDAHULUAN}

Kehamilan tidak semua dapat berjalan dengan lancar, pada kondisi hamil, sering ditemukan berbagai risiko yang dapat mempengaruhi kesehatan dan mengancam jiwa ibu maupun kandungannya. Diantara beberapa permasalahan yang sering dijumpai adalah hipertensi pada masa kehamilan. Kondisi ini mengakibatkan tingginya angka kesakitan dan kematian yang pada akhirnya menjadi permasalahan kesehatan masyarakat secara umum. ${ }^{[1]}$

Wanita hamil memiliki risiko terjadinya komplikasi yang dapat menyebabkan kematian salah satunya adalah anemia dalam kehamilan. Anemia pada kehamilan merupakan salah satu masalah nasional karena mencerminkan nilai kesejahteraan sosial ekonomi masyarakat dan pengaruhnya sangat besar terhadap kualitas sumber daya manusia. Anemia pada ibu hamil disebut "Potensial danger to mother and child" (potensial membahayakan ibu dan anak). Oleh karena itulah anemia memerlukan perhatian serius dari semua pihak yang terkait dalam pelayanan kesehatan. $^{[2]}$

Anemia adalah suatu keadaan dimana tubuh memiliki jumlah sel darah merah (eritrosit) yang terlalu sedikit, yang mana sel darah merah itu mengandung hemoglobin yang berfungsi untuk membawa oksigen ke seluruh jaringan tubuh. Anemia dalam kehamilan dapat berpengaruh buruk terutama saat kehamilan, persalinan dan nifas. $^{[3]}$

Anemia di Indonesia umumnya disebabkan oleh kekurangan zat besi, sehingga lebih dikenal dengan istilah anemia gizi besi. Anemia defisiensi besi merupakan salah satu gangguan yang paling sering terjadi selama kehamilan. Ibu hamil umumnya mengalami deplesi besi sehingga hanya memberi sedikit besi kepada janin yang dibutuhkan untuk metabolisme besi yang normal. Selanjutnya mereka akan menjadi anemia pada saat kadar hemoglobin ibu turun sampai dibawah $11 \mathrm{gr} / \mathrm{dl}$ selama trimester III. $^{[4]}$ Anemia masih merupakan suatu masalah manusia di permukaan bumi. Anak anak dan ibu hamil menduduki peringkat tertinggi yang mengalami anemia. ${ }^{[5]}$

Ketidakpatuhan ibu hamil mengkonsumsi tablet Fe dan kurangnya pengetahuan tentang pentingnya zat besi untuk kehamilannya menjadi salah satu faktor terjadinya anemia pada ibu hamil. Anemia dalam kehamilan sebenarnya dapat diobati atau ditangani.Penanganan kasus anemia dalam kehamilan dilakukan dengan berbagai cara. Penyuluhan-penyuluhan yang dilakukan oleh petugas kesehatan, serta pemberian suplemen tablet besi-folat atau tablet tambah darah yang dikonsumsi secara teratur telah dilakukan oleh pemerintah sejak tahun 1974. ${ }^{[6]}$

Penelitian serupa menunjukkan hasil, dari $33 \mathrm{ibu}$ hamil trimester III di Wilayah Kerja Puskesmas Binangun Kabupaten Blitar, ditemukan bahwa sebagian besar $11(33 \%)$ ibu mengalami anemia ringan, $9(27 \%)$ anemia sedang, $7(22 \%)$ anemia berat dan hanya $6(18 \%)$ ibu tidak mengalami anemia saat hamil. ${ }^{[7]}$

Menurut WHO (2015) ${ }^{[8]}$, secara global prevalensi anemia pada ibu hamil di seluruh dunia adalah sebesar 51,2\%. Prevalensi anemia pada ibu hamil diperkirakan di Asia sebesar 45,2 \%, Afrika 50,1\%, Amerika 27,3\%, dan Eropa $25,8 \%$. Berdasarkan Kementerian Kesehatan Republik Indonesia tahun 2018, angka rendahnya cakupan pemberian tablet Fe3 mencapai 52,23\%. Tertinggi berada di Gorontalo 76,28\%, 
Jambi 71,31\%, Sulawesi Tengah 69,27\%, dan Aceh 52,74\% (Kemenkes RI, 2018). Berdasarkan data provinsi Aceh angka ibu hamil mengkonsumsi tablet $\mathrm{Fe} 3$ sejumlah 90 tablet pada tahun 2018 sebesar 52,74\%. Terendah berada di daerah Simeulue sebesar 58\%, Aceh Besar sebesar 51\%, Aceh Singkil 65\%, Aceh Timur 68\%, dan Aceh Tengah 72\% (Dinkes Aceh, 2018).

Adapun data dari Dinas Kesehatan Aceh Besar jumlah ibu hamil mengkonsumsi tablet $\mathrm{Fe} 3$ sejumlah 90 tablet pada tahun 2018 sebesar 51,37\%. Angka terendah berada di Kecamatan Blang Bintang 53,7\%, Kecamtan Ingin Jaya 54,47\%, Kecamatan Lampisang 20\%, dan Pulo Aceh 61,4\% (Dinkes Aceh Besar, 2018).

Berdasarkan pengambilan data awal di Puskesmas Lampisang semakin menurun cakupan tablet $\mathrm{Fe} 3$ pada ibu

\section{METODE}

Jenis penelitian yang dilakukan adalah survey analitik dan menggunakan desain cross sectional dengan pendekatan kuantitatif. Populasi pada penelitian ini adalah seluruh ibu hamil Wilayah Kerja Puskesmas Lampisang Kabupaten Aceh Besar Tahun 2019, sebanyak 276 ibu hamil,

Sampel pada penelitian ini sebanyak 73 orang, berdasarkan rumus Slovin. Teknik pengambilan sampel dilakukan secara non random sampling.

\section{HASIL}

Analisis bivariat menggunakan uji Chi-Square yaitu untuk mencari hubungan antara variabel peran petugas kesehatan, kepatuhan ibu hamil dan dukungan keluarga dengan pemberian tablet $\mathrm{Fe} 3$ pada ibu hamil, dapat dilihat sebagai berikut: hamil tahun 2018 sebesar $88 \%$ ibu hamil menurun tahun 2019 cakupan konsumsi tablet $\mathrm{Fe} 3$ pada ibu hamil hanya sebesar 56 ibu hamil (20\%). Tertinggi cakupan pemberian tablet Fe3 di Gampong Ajun yaitu 17 ibu hamil, Gampong Lam Hasan 15 ibu hamil, Gampong Rima Jeuneu 7 ibu hamil, Gampong Lampisang 5 ibu hamil, Gampong Keuneu'eu 5 ibu hamil, Gampong Beuradeun 3 ibu hamil dan terendah Rima Keuneurum 2 ibu hamil, Gampong Payating 2 ibu hamil.

Berdasarkan fenomena diatas, maka peneliti tertarik untuk melakukan penelitian lebih lanjut tentang "Faktor Yang Berhubungan Dengan Rendahnya Cakupan Pemberian Tablet Fe3 Pada Ibu Hamil Di Wilayah Kerja Puskesmas Lampisang Kabupaten Aceh Besar Tahun 2019".

Untuk tiap desa dilakukan dengan cara mengambil beberapa sampel dari populasi tiap desa dengan rumus porportional sampling. Setelah diambil sampel tiap desa. Lalu peneliti membagikan kuesioner kepada 73 responden, pengambilan sampel yang memperhatikan pertimbangan unsurunsur atau kategori dalam populasi penelitian tersebut. Pengumpulan data menggunakan instrumen penelitian kuisioner, analisis data bersifat kuantitatif/statistik menggunakan univariat dan bivariat.

Berdasarkan [Tabel.1], diketahui bahwa dari 33 responden yang peran petugas kesehatannya berperan dalam pemberian tablet $\mathrm{Fe} 3$ pada ibu hamil maka diperoleh sebanyak 21 responden $(63,6 \%)$ yang cakupan pemberian tablet Fe3 tercapai. Sedangkan dari 40 responden yang peran petugas kesehatan tidak berperan dalam pemberian tablet 
Fe3 pada ibu hamil maka diperoleh sebanyak 35 responden $(87,5 \%)$ yang cakupan pemberian tablet $\mathrm{Fe} 3$ tidak tercapai. Hasil uji statistik dengan menggunakan uji chi square test pada tingkat kepercayaan $95 \% \quad(\alpha=0,05)$ didapatkan nilai $\mathrm{P}$ value $=0,001$ ( $\mathrm{p}<$ $0,05)$. Ha terbukti yang artinya ada hubungan antara peran petugas kesehatan dengan rendahnya cakupan pemberian Tablet Fe3 Pada Ibu Hamil.

Dukungan dikeluarga diketahui, dari 40 responden yang ada dukungan keluarga dalam pemberian tablet $\mathrm{Fe} 3$ pada ibu hamil maka diperoleh sebanyak 21 responden $(52,5 \%)$ yang cakupan pemberian tablet $\mathrm{Fe} 3$ tercapai. Sedangkan dari 33 responden yang tidak ada dukungan keluarga dalam pemberian tablet $\mathrm{Fe} 3$ pada ibu hamil maka diperoleh sebanyak 28 responden $(84,8 \%)$ yang cakupan pemberian tablet Fe3 tidak tercapai. Hasil uji statistik dengan menggunakan uji chi square test pada tingkat kepercayaan $95 \%(\alpha=0,05)$ didapatkan nilai $\mathrm{P}$ value $=0,001$ ( $\mathrm{p}<$

\section{PEMBAHASAN}

\section{Peran Petugas Kesehatan Dengan Rendahnya Cakupan Pemberian Tablet Fe3 Pada Ibu Hamil}

Secara garis besar ada perananperanan penting yang harus dilakukan oleh tenaga kesehatan sebagai kader kesehatan masyarakat diantaranya yaitu melakukan promosi kesehatan, melakukan tindakan dan perawatan secara komprehensif pada pasien, memberikan dukungan, dan melakukan rujukan. ${ }^{[5]}$

Menurut Sulistyowati (2011) ${ }^{[5]}$ secara garis besar ada perananperanan penting yang harus dilakukan oleh tenaga kesehatan sebagai kader kesehatan masyarakat diantaranya yaitu melakukan promosi kesehatan,
0,05). Ha terbukti yang artinya ada hubungan antara dukungan keluarga dengan rendahnya cakupan pemberian tablet Fe3 Pada Ibu hamil.[Tabel.2].

Dari hasil [Tabel.3], dapat diketahui bahwa dari 29 responden yang patuh dalam pemberian tablet $\mathrm{Fe} 3$ pada ibu hamil maka diperoleh sebanyak 19 responden $(65,6 \%)$ yang cakupan pemberian tablet $\mathrm{Fe} 3$ tercapai. Sedangkan dari 44 responden yang tidak patuh dalam pemberian tablet $\mathrm{Fe} 3$ pada ibu hamil maka diperoleh sebanyak 37 responden $(84,1 \%)$ yang cakupan pemberian tablet $\mathrm{Fe} 3$ tidak tercapai. Hasil uji statistik dengan menggunakan uji chi square test pada tingkat kepercayaan $95 \%(\alpha=0,05)$ didapatkan nilai $\mathrm{P}$ value $=0,001 \quad(\mathrm{p}<0,05)$. Ha terbukti yang artinya ada hubungan antara keptuhan ibu hamil dengan rendahnya cakupan pemberian tablet $\mathrm{Fe} 3$ Pada Ibu hamil Di Wilayah Kerja Puskesmas Lampisang Kabupaten Aceh Besar Tahun 2019.

melakukan tindakan dan perawatan secara komprehensif pada pasien, memberikan dukungan, dan melakukan rujukan. Penelitian ini memfokuskan peran tenaga kesehatan sebagai komunikator, motivator, fasilitator dan konselor.

Hasil penelitian ini sejalan dengan penelitian yang dilakukan oleh Meldia Putri tahun 2016 dengan judul Hubungan Peran Tenaga Kesehatan dan Kepatuhan Ibu Hamil Terhadap Pemberian Tablet Fe3 Pada Ibu Hamil Di Puskesms Pleret Kabupaten Bantul Yogyakarta. Hasil penelitian menunjukan bahwa peran petugas kesehatan kurang baik sebanyak 94,4\% dengan pemberian tablet Fe3 tidak tercapai. Sedangkan 
peran petugas kesehatan baik sebanyak $5,6 \%$ dengan pemberian tablet Fe3 tercapai. Hasil uji chi square diperoleh $\mathrm{p}$ value $=0,001$ yang artinya ada hubungan hubungan peran tenaga kesehatan terhadap pemberian tablet fe3 pada ibu hamil di Puskesms Pleret Kabupaten Bantul Yogyakarta.

\section{Dukungan Keluarga Kesehatan Dengan Rendahnya Cakupan Pemberian Tablet Fe3 Pada Ibu Hamil}

Tugas keluarga bidang kesehatan antara lain adalah mengenal masalah kesehatan setiap anggota keluarganya termasuk ibu hamil. Mengambil keputusan untuk melakukan tindakan yang tepat bagi keluarga. Memberikan keperawatan anggotanya yang sakit atau yang tidak dapat membantu dirinya sendiri karena cacat atau usianya terlalu muda. Mempertahankan suasana dirumah yang menguntungkan kesehatan dan perkembangan kepribadian anggota keluarga. ${ }^{[9]}$

Kecemasan yang dialami ibu hamil sangat berpengaruh dengan keadaan kesehatan janin.Kesehatan ibu hamil sangat ditentukan oleh kesehatan jiwanya. Oleh karena itu, ibu hamil sangat membutuhkan dukungan emosional dan psikologi untuk kesanggupan menyesuaikan diri selama proses kehamilan, persalinan dan menjadi ibu. ${ }^{[10]}$ Dukungan kebutuhan emosional dan psikologis dari keluarga yang tidak terpenuhi menimbulkan ancaman pada kehidupan.Perubahan sosial ancaman kehidupan tersebut menjadikan keluarga sebagai pengaruh penurunan pada individu anggotanya. ${ }^{[6]}$

Hasil penelitian ini sejalan dengan penelitian yang dilakukan oleh Ratna Juwita tahun 2018 dengan judul Hubungan Konseling dan Dukungan Keluarga Terhadap Pemberian Tablet Fe3 Pada Ibu Hamil di Wilayah Kerja Puskesmas Sikijang Kabupaen Pelalawan. Hasil penelitian menunjukan bahwa tidak ada dukungan keluarga sebanyak 62,9\% dengan pemberian tablet $\mathrm{Fe} 3$ tidak tercapai. Sedangkanada dukungan keluarga sebanyak $37,1 \%$ dengan pemberian tablet $\mathrm{Fe} 3$ tercapai. Hasil uji chi square diperoleh $\mathrm{p}$ value $=$ 0,010 yang artinya ada hubungan konseling dan dukungan keluarga terhadap pemberian tablet $\mathrm{Fe} 3$ pada Ibu Hamil di Wilayah Kerja Puskesmas Sikijang Kabupaen Pelalawan.

\section{Kepatuhan Ibu Hamil Dengan Rendahnya Cakupan Pemberian Tablet Fe3 Pada Ibu Hamil}

Kepatuhan ibu hamil terhadap tablet $\mathrm{Fe}$ dipengaruhi oleh tingkat pendidikan yang pernah dijalani, jumlah kunjungan antenatal yang pernah dilakukan, pengetahuan mengenai status hemoglobin dan dosis tablet Fe yang harus dikonsumsi setiap harinya. Kepatuhan ibu hamil dinilai dari sikap ibu dalam mengikuti instruksi mengkonsumsi tablet $\mathrm{Fe}$ yang diberikan oleh petugas kesehatan setempat. ${ }^{[10]}$

Kepatuhan ibu hamil mengkonsumsi tablet besi sangat dipengaruhi oleh diri ibu sendiri dalam menyadari pentingnya tablet besi bagi dirinya dan bayinya teruatam untuk kesehatannya agar selalu dalam kondisi prima, maka ia akan mengkonsumsi tablet $\mathrm{Fe}$ sesuai dengan yang dianjurkan. ${ }^{[11]}$

Hasil penelitian ini sejalan dengan penelitian yang dilakukan oleh Meldia Putri tahun 2016 dengan 
judul Hubungan Peran Tenaga Kesehatan dan Kepatuhan Ibu Hamil Terhadap Pemberian Tablet Fe3 Pada Ibu Hamil Di Puskesms Pleret Kabupaten Bantul Yogyakarta. Hasil penelitian menunjukan bahwa ibu hamil yang patuh sebanyak 15,8\% dengan pemberian tablet $\mathrm{Fe} 3$ tercapai.

\section{KESIMPULAN DAN SARAN}

Dari hasil penelitian ini dapat disimpulkan bahwa:

Ada hubungan antara peran petugas kesehatan dengan rendahnya cakupan pemberian Tablet Fe3 Pada Ibu Hamil, dengan nilai p-value $=0,001$.

Terdapat hubungan antara dukungan keluarga dengan rendahnya cakupan pemberian Tablet Fe3 pada Ibu Hamil, dengan nilai p-value $=0,001$.

Diperoleh hubungan antara kepatuhan ibu hamil dengan rendahnya cakupan pemberian Tablet Fe3 Pada Ibu Hamil Di Wilayah Kerja Puskesmas Lampisang Kabupaten Aceh Besar Tahun 2019, dengan nilai pvalue $=0,001$.

\section{DAFTAR PUSTAKA}

1. Chan XK 2006 dalam: Rafsanjani, T. M., Yasir, Y., \& Masyudi, M. (2019). Hubungan Pola Makan, Umur Dan Pengetahuan Dengan Kejadian Hipertensi Pada Ibu Hamil Di Wilayah Kerja Puskesmas Krueng Barona Jaya Kabupaten Aceh Besar. Journal of public health research and community health development, 3(1), 63-70.

2. Rohmah, (2013). Analisis Faktor Penyebab Terjadinya Anemia Pada Ibu Hamil Diwilayah Kerja Puskesmas Tawangsari Kabupaten Sukoharjo. Skripsi Keperawatan. Surakarta:UNMUHA.
Sedangkan ibu hamil yang tidak patuh sebanyak $85,8 \%$ dengan pemberian tablet $\mathrm{Fe} 3$ tidak tercapai. Hasil uji chi square diperoleh $\mathrm{p}$ value $=0,001$ yang artinya ada hubungan kepatuhan ibu hamil terhadap pemberian tablet fe3 pada ibu hamil di Puskesms Pleret Kabupaten Bantul Yogyakarta.

Disarankan bagi Tenaga Kesehatan yang memberikan pelayanan Ante Natal Care (ANC) yaitu dokter dan bidan diharapkan meningkatkan kegiatan promosi kesehatan pada ibu hamil tentang pentingnya mengkonsumsi tablet Fe pada ibu hamil dengan cara memasukkan materi tersebut dalam kegiatan promosi kesehatan selama pelayanan Ante Natal Care di Posyandu dan Puskesmas.

Bagi Ibu Hamil Diharapkan bagi ibu hamil sebaiknya mengkonsumsi zat besi sejak masa prahamil dibutuhkan untuk mengisi cadangan zat besi dengan mengkonsumsi sayur dan buah yang mengandung zat besi seperti jeruk, apel, anggur dan buah lainnya yang mengandung zat besi tinggi.

3. Proverawati, (2011). Anemia dan Anemia Kehamilan. Yogyakarta: Nuha Medika

4. Waryana, (2010). Gizi Reproduksi. Yogyakarta: Pustaka Rahima

5. Masyudi, M. (2018). Pemeriksaan Haemoglobin Ibu Hamil di Puskesmas Penanggalan Kota Subulussalam. Serambi Saintia: Jurnal Sains dan Aplikasi, 6(1).

6. Depkes RI, (2011). Profil Kesehatan Indonesia tahun 2011. Jakarta : Depkes RI.

7. Eva, I. (2015). Karakteristik Yang Mempengaruhi Kejadian Anemia Pada Ibu Hamil Di Wilayah Kerja 
Puskesmas Binangun Kabupaten Blitar. Jurnal. Stikes Kendedes.

8. WHO (2015), The Global Prevalence of Anemia in 2011. Switzerland : WHO.

9. Farrer,H. (2010). Perawatan Maternitas: Alih Bahasa Andry Hartono.Ed.2, Jakarta: EGC.
10. Efendi, (2010). Keperawatan Kesehatan Komunitas: Teori dan Praktik dalam Keperawatan, Jakarta: Salemba Medika.

11. Arisman, (2010). Gizi dalam Daur Kehidupan. Jakarta: EGC 


\section{LAMPIRAN}

Tabel [1]. Hubungan Antara Peran Petugas Kesehatan Dengan Rendahnya Cakupan Pemberian Tablet Fe3 Pada Ibu Hamil Di Wilayah Kerja Puskesmas Lampisang Kabupaten Aceh Besar Tahun 2019

\begin{tabular}{|c|c|c|c|c|c|c|c|c|c|}
\hline \multirow{3}{*}{ No } & \multirow{3}{*}{$\begin{array}{l}\text { Peran Petugas } \\
\text { Kesehatan }\end{array}$} & \multicolumn{4}{|c|}{ Pemberian Tablet Fe3 } & \multirow{2}{*}{\multicolumn{2}{|c|}{ Total }} & \multirow{3}{*}{ P value } & \multirow{3}{*}{$\alpha$} \\
\hline & & \multicolumn{2}{|c|}{ Tecapai } & \multicolumn{2}{|c|}{$\begin{array}{c}\text { Tidak } \\
\text { Tercapai } \\
\end{array}$} & & & & \\
\hline & & $\mathbf{f}$ & $\%$ & $\mathbf{f}$ & $\%$ & $\mathbf{f}$ & $\%$ & & \\
\hline 1 & Berperan & 21 & 63,6 & 12 & 36,4 & 33 & 100 & \multirow{3}{*}{0,001} & \multirow{3}{*}{0,05} \\
\hline 2 & Tidak Berperan & 5 & 12,5 & 35 & 87,5 & 40 & 100 & & \\
\hline & Total & 26 & 35,6 & 47 & 64,4 & 73 & 100 & & \\
\hline
\end{tabular}

Sumber : Data primer (Diolah September 2019)

Tabel [2]. Hubungan Antara Dukungan Keluarga Dengan Rendahnya Cakupan Pemberian Tablet Fe3 Pada Ibu Hamil Di Wilayah Kerja Puskesmas Lampisang Kabupaten Aceh Besar Tahun 2019

\begin{tabular}{|c|c|c|c|c|c|c|c|c|c|}
\hline \multirow{3}{*}{ No } & \multirow{3}{*}{$\begin{array}{c}\text { Dukungan } \\
\text { Keluarga }\end{array}$} & \multicolumn{4}{|c|}{ Pemberian Tablet Fe3 } & & & \multirow{3}{*}{ P value } & \multirow{3}{*}{$\boldsymbol{\alpha}$} \\
\hline & & \multicolumn{2}{|c|}{ Tecapai } & \multicolumn{2}{|c|}{$\begin{array}{c}\text { Tidak } \\
\text { Tercapai }\end{array}$} & \multicolumn{2}{|c|}{ Total } & & \\
\hline & & $\mathbf{f}$ & $\%$ & $\mathbf{F}$ & $\%$ & $\mathbf{f}$ & $\%$ & & \\
\hline 1 & Ada & 21 & 52,5 & 19 & 47,5 & 40 & 100 & \multirow{3}{*}{0,001} & \multirow{3}{*}{0,05} \\
\hline 2 & Tidak Ada & 5 & 15,2 & 28 & 84,8 & 33 & 100 & & \\
\hline & Total & 26 & 35,6 & 47 & 64,4 & 73 & 100 & & \\
\hline
\end{tabular}

Sumber : Data primer (Diolah September 2019)

Tabel [3]. Hubungan Antara Kepatuhan Ibu Hamil Dengan Rendahnya Cakupan Pemberian Tablet Fe3 Pada Ibu Hamil Di Wilayah Kerja Puskesmas Lampisang Kabupaten Aceh Besar Tahun 2019

\begin{tabular}{|c|c|c|c|c|c|c|c|c|c|}
\hline \multirow{3}{*}{ No } & \multirow{3}{*}{$\begin{array}{l}\text { Kepatuhan } \\
\text { Ibu Hamil }\end{array}$} & \multicolumn{4}{|c|}{ Pemberian Tablet Fe3 } & \multirow{2}{*}{\multicolumn{2}{|c|}{ Total }} & \multirow{3}{*}{ P value } & \multirow{3}{*}{$\boldsymbol{\alpha}$} \\
\hline & & \multicolumn{2}{|c|}{ Tecapai } & \multicolumn{2}{|c|}{$\begin{array}{c}\text { Tidak } \\
\text { Tercapai }\end{array}$} & & & & \\
\hline & & $\mathbf{f}$ & $\%$ & $\mathbf{F}$ & $\%$ & $\mathbf{F}$ & $\%$ & & \\
\hline 1 & Patuh & 19 & 65,6 & 10 & 34,5 & 29 & 100 & \multirow{3}{*}{0,001} & \multirow{3}{*}{0,05} \\
\hline 2 & Tidak Patuh & 7 & 15,9 & 37 & 84,1 & 44 & 100 & & \\
\hline & Total & 26 & 35,6 & 47 & 64,4 & 73 & 100 & & \\
\hline
\end{tabular}

Sumber : Data primer (Diolah September 2019) 